\title{
Granulocyte Macrophage Colony Stimulating Factor Treatment is Associated with Improved Cognition in Cancer Patients
}

\author{
Heather SL Jim ${ }^{1 *}$, Tim D Boyd ${ }^{2}$, Margaret Booth-Jones ${ }^{1}$, Joseph Pidala ${ }^{1}$ and Huntington Potter ${ }^{1,2 *}$ \\ ${ }^{1}$ Moffitt Cancer Center, 12902 Magnolia Drive MRC-PSY, Tampa, FL, USA \\ ${ }^{2}$ Pfeiffer Suncoast Gerontology Center and Byrd Alzheimer's Institute, University of South Florida, 4001 E. Fletcher Ave. Tampa, FL, USA
}

\begin{abstract}
Background: Endogenous Granulocyte Macrophage Colony Stimulating Factor (GMCSF) is released in rheumatoid arthritis patients, who are largely protected from Alzheimer's disease (AD). Introducing exogenous GMCSF into an $A D$ mouse model reduced amyloid deposition by $55 \%$ and restored normal cognition. No published studies have examined exogenous GMCSF and cognitive functioning in humans.
\end{abstract}

Objectives/ Design: The goal of the current study was to examine the association between receipt of GMCSF and cognitive functioning in patients receiving colony stimulating factors as part of routine supportive care for hematopoietic cell transplantation (HCT).

Setting and Participants: Archived neuropsychological data were examined from a longitudinal study of cognitive functioning in 95 patients receiving HCT at the Moffitt Cancer Center.

Intervention: Receipt of GMCSF and/or Granulocyte Colony Stimulating Factor (GCSF) was ascertained through patient billing records.

Measurements: Patients were assessed with a battery of neuropsychological tests prior to transplant and 6 and 12 months post-transplant.

Results: Patients treated with GMCSF and GCSF $(n=19)$ showed significantly greater improvement in total neuropsychological functioning (TNP) at 6 months than patients treated with GCSF only $(n=76)(p=.04)$. There was no group difference in TNP at 12 months $(p=.24)$. Improvement in TNP from baseline to 6 months post-HCT was significant in the GMCSF+GCSF group $(p=.01)$ but not the GCSF only group $(p=.33)$. Improvement in TNP from baseline to 12 months post-HCT was significant in both groups (ps<.01).

Conclusion: Preliminary data from this study of humans receiving colony stimulating factors suggest that receipt of GMCSF+GCSF was associated with greater cognitive improvement than GCSF alone. Randomized controlled trials of the effects of GMCSF on cognitive functioning in humans are warranted and underway to confirm these findings.

Keywords: Neoplasms; Alzheimer's disease; Autoimmune diseases; Granulocyte-macrophage colony-stimulating factor; Neurobehavioral manifestations; Hematopoietic cell transplantation

\section{Introduction}

Cognitive decline is a major societal concern due to the aging population of many industrialized nations. Cognitive decline not only results from the aging process itself, but also neurodegenerative diseases such as Alzheimer's disease (AD) and some treatments for other common age-related diseases, such as cancer [1-3]. Thus far, no effective pharmacologic treatment that reverses cognitive decline has been developed for any indication.

One potentially promising treatment is granulocyte macrophage colony stimulating factor (GMCSF). Clinical interest in GMCSF developed out of the observation that patients with Rheumatoid Arthritis (RA) are at 8-fold reduced risk of developing AD. This finding was originally hypothesized to result from patients' use of Non-Steroidal Anti-inflammatory Drugs (NSAIDs) [4]. Although early findings showed inflammation proteins playing an essential role in $\mathrm{AD}$ [5], NSAIDs trials in AD were largely negative [6]. Instead, endogenous factors, specifically several colony stimulating factors (CSFs) released during RA, might activate the innate immune system and thereby also reduce pathology and promote neurogenesis and angiogenesis in the $\mathrm{AD}$ brain [7].

Experimental research in mice has found that a single injection of GMCSF or granulocyte colony stimulating factor (GCSF) into one side of the brain reduced amyloid deposition by up to $40 \%$ in 7 days compared to the vehicle injected side, with GMCSF being more efficacious than GCSF $[7,8]$. These findings were confirmed by additional experiments examining neuronal and behavioral outcomes after sub-cutaneous administration of GMCSF or GCSF $[7,8]$. Compared to GCSF, GMCSF exhibited greater impact on cognition, which returned to normal These findings, along with two decades of excellent safety data from the administration of recombinant human GMCSF (sargramostim) to elderly leukopenic patients suggests that CSFs, particularly GMCSF should be tested in randomized controlled trials as a treatment to halt or reverse cognitive impairment in humans [7].

The aim of the present study was to provide preliminary

*Corresponding authors: Huntington Potter, Byrd Alzheimer's Institute, University of South Florida, 4001 E. Fletcher Ave. Tampa, FL 33613, Tel: 813-974-5369; Fax: 813-971-0373; E-mail: hpotter@health.usf.edu

Heather S. Jim, Moffitt Cancer Center, 12902 Magnolia Drive MRC-PSY Tampa, FL, USA, Tel: 813-745-6369; Fax: 813-745-3906; E-mail: heather.jim@moffitt.org

Received February 15, 2012; Accepted April 06, 2012; Published April 10, 2012

Citation: Jim HSL, Boyd TD, Booth-Jones M, Pidala J, Potter H (2012) Granulocyte Macrophage Colony Stimulating Factor Treatment is Associated with Improved Cognition in Cancer Patients. Brain Disorders Ther 1:101. doi:10.4172/2168975X.1000101

Copyright: ( $2012 \mathrm{Jim} \mathrm{HSL}$, et al. This is an open-access article distributed unde the terms of the Creative Commons Attribution License, which permits unrestricted use, distribution, and reproduction in any medium, provided the original author and source are credited. 
Citation: Jim HSL, Boyd TD, Booth-Jones M, Pidala J, Potter H (2012) Granulocyte Macrophage Colony Stimulating Factor Treatment is Associated with Improved Cognition in Cancer Patients. Brain Disorders Ther 1:101. doi:10.4172/2168-975X.1000101

Page 2 of 4

observational data in support of such trials. Because CSFs are routinely administered to cancer patients undergoing autologous HCT, and HCT is associated with transient cognitive decline $[9,10]$, this population provides an ideal opportunity to study cognitive functioning related to receipt of GMCSF. It was hypothesized that HCT patients treated with GMCSF would display greater increases in cognitive functioning over time compared to patients treated with GCSF.

\section{Methods and Materials}

We examined archived neuropsychological data from a longitudinal study of the cognitive function of patients at Moffitt Cancer Center [11]. GMCSF and GCSF are used as part of routine supportive care to mobilize stem cells for autologous HCT, speed engraftment after autologous HCT, and/or treat neutropenia following allogeneic HCT. Choice of GMCSF+GCSF versus GCSF alone was based solely on availability and/or reimbursement options and was not related to clinical or sociodemographic factors or desire of the patient.

Following Institutional Review Board approval, patients were recruited between February 2001 and September 2004. To be eligible for the larger study, patients had to: 1) be between 18 and 75 years of age, 2) have completed at least 8 years of education, 3) be able to speak and read English, 4) be scheduled to receive HCT, 5) plan to return to Moffitt for follow-up assessments, and 6) be able to provide informed consent. Prior to stem cell mobilization and HCT, patients completed a baseline neuropsychological assessment and provided sociodemographic information [11]. Follow-up neuropsychological assessments were conducted at 6 months and 12 months post-HCT. Neuropsychological tests are listed in (Table 1). Patients who completed a baseline neuropsychological assessment and at least one followup assessment were selected for the current analyses. Patients who received all administrations of GMCSF and/or GCSF at a location other than Moffitt were excluded from the analyses.

Data regarding receipt of GMCSF (i.e., sargramostim) and/or GCSF (i.e, filgrastim, pegfilgrastim) were collected via patient billing records. For the current analyses, total neuropsychological performance $\mathrm{z}$ scores (TNP) were calculated by summarizing the cognitive domains of memory, executive functioning (i.e., complex cognition), and attention. Scores indicate change in TNP from pre-transplant baseline. KruskalWallis one-way analyses of variance were conducted using all available data to compare between-group changes in TNP by receipt of GMCSF at Times 2 and 3. Wilcoxon signed rank tests were conducted using all available data to examine within-group changes in TNP by receipt of GMCSF.

\begin{tabular}{|l|l|}
\hline Cognitive domain & Neuropsychological Tests \\
\hline Memory & CVLT-II [26] \\
\hline & WMS-III Logical Memory subtest [27] \\
\hline Executive function & $\begin{array}{l}\text { WMS-III Visual Reproduction subtest } \\
{[27]}\end{array}$ \\
\hline & WAIS-R Digit Symbol [28] \\
\hline & Trailmaking Test [29] \\
\hline & COWA [30] \\
\hline Attention & Stroop Neuropsychological Screening \\
& Test [31] \\
\hline
\end{tabular}

Note: COWA: Controlled Oral Word Association Test, CPT-II: Connors' Continuous Performance Test - II, CVLT-II: California Verbal Learning Test - II, WAIS-R: Wechsler Adult Intelligence Scale - Revised, WMS-III: Wechsler Memory Test - III.

Table 1: Neuropsychological Tests Administered.

\section{Results}

Of 286 participants who signed consent and completed a baseline assessment, 182 had no follow-up data, 4 had received GMCSF and/ or GCSF elsewhere, and 5 had not received GMCSF or GCSF, leaving a final sample of 95 participants. Of these, 89 participants had baseline and 6 month follow-up data, 63 had baseline and 12 month data, and 57 had data at all 3 assessment points. A total of 19 patients received GMCSF+GCSF, and 76 received GCSF only. No patients received GMCSF only. Patients had a mean age of 51 (range 21-72), $48 \%$ were female, $83 \%$ were Caucasian, and $32 \%$ had graduated from college. Most patients were diagnosed with multiple myeloma or non-Hodgkin's lymphoma (78\%) and received autologous HCT (83\%) (Table 2).

Despite a high level of education (average of 13.89 years), participants displayed a statistically significant cognitive deficit at baseline [11]. The results (Figure 1) show that the GMCSF+GCSF group performed significantly better than the GCSF only group at 6 months post-HCT $(\mathrm{p}=.04)$, but there were no group difference at 12 months post-HCT $(\mathrm{p}=.24)$. Change in TNP from baseline to 6 months post-HCT was significant in the GMCSF+GCSF group ( $\mathrm{p}=.01$ ) but not

\begin{tabular}{|c|c|c|c|}
\hline & GMCSF+GCSF $(n=19)$ & $\begin{array}{l}\text { GCSF Only } \\
(n=76)\end{array}$ & $p$ \\
\hline Age: Mean (SD) & $58.06(8.22)$ & $50.41(11.90)$ & .01 \\
\hline $\begin{array}{l}\text { Years of Education: Mean } \\
\text { (SD) }\end{array}$ & $14.11(2.56)$ & $14.00(2.96)$ & .59 \\
\hline $\begin{array}{l}\text { Estimated Premorbid IQ: } \\
\text { Mean (SD) }\end{array}$ & $105.05(9.22)$ & $105.80(11.22)$ & .69 \\
\hline $\begin{array}{l}\text { Baseline Functional Status } \\
\text { ECOG }\end{array}$ & $1.32(.89)$ & $1.05(.80)$ & .27 \\
\hline \multirow[t]{3}{*}{ Gender } & & & .44 \\
\hline & Female & $11(58 \%)$ & $35(46 \%)$ \\
\hline & Male & $8(42 \%)$ & $41(54 \%)$ \\
\hline \multirow[t]{3}{*}{ Race } & & & .73 \\
\hline & Caucasian & $15(79 \%)$ & $64(84 \%)$ \\
\hline & Non-Caucasian & $4(21 \%)$ & $12(16 \%)$ \\
\hline \multirow[t]{12}{*}{ Diagnosis } & & & .09 \\
\hline & Multiple Myeloma & $17(89 \%)$ & $51(67 \%)$ \\
\hline & $\begin{array}{l}\text { Acute Myelogenous } \\
\text { Leukemia }\end{array}$ & $1(5 \%)$ & $3(4 \%)$ \\
\hline & $\begin{array}{l}\text { Myelodysplastic Syn- } \\
\text { drome }\end{array}$ & $0(0 \%)$ & $2(3 \%)$ \\
\hline & $\begin{array}{l}\text { Acute Lymphoblastic } \\
\text { Leukemia }\end{array}$ & $0(0 \%)$ & $1(1 \%)$ \\
\hline & Breast Carcinoma & $1(5 \%)$ & $5(7 \%)$ \\
\hline & $\begin{array}{l}\text { Chronic Lymphocytic } \\
\text { Leukemia }\end{array}$ & $0(0 \%)$ & $1(1 \%)$ \\
\hline & $\begin{array}{l}\text { Chronic Myelogenous } \\
\text { Leukemia }\end{array}$ & $0(0 \%)$ & $2(3 \%)$ \\
\hline & $\begin{array}{l}\text { Myeloproliferative } \\
\text { neoplasm }\end{array}$ & $0(0 \%)$ & $1(1 \%)$ \\
\hline & Hodgkin's Lymphoma & $0(0 \%)$ & $2(3 \%)$ \\
\hline & $\begin{array}{l}\text { Non Hodgkin's Lym- } \\
\text { phoma }\end{array}$ & $0(0 \%)$ & $6(8 \%)$ \\
\hline & Aplastic Anemia & $0(0 \%)$ & $2(3 \%)$ \\
\hline \multirow[t]{3}{*}{ Transplant type } & & & .18 \\
\hline & Autologous & $18(95 \%)$ & $61(80 \%)$ \\
\hline & Allogeneic & $1(5 \%)$ & $15(20 \%)$ \\
\hline
\end{tabular}

Note: Kruskal-Wallace one way analyses of variance were used to compare GMCSF+GCSF, and GCSF only groups on age, years of education, estimated premorbid IQ, and ECOG. Fisher's exact tests were used to compare GMCSF+GCSF and GCSF only groups on gender, race, diagnosis, and transplant type. Diagnosis was coded as Multiple Myeloma versus other.

Table 2: Categories of gender, race, diagnosis, transplant type need to be moved to the left in a new column so that the numbers correspond to the column headings of GMCSF+GCSF and GCSF only. 


\begin{tabular}{|l|l|l|l|l|}
\hline & \multicolumn{2}{|c|}{ GMCSF+GCSF } & \multicolumn{2}{c|}{ GCSF Only } \\
\hline & 6 Months & 12 Months & 6 Months & 12 Months \\
\hline TNP & $.19(.27)$ & $.34(.43)$ & $.03(.30)$ & $.24(.33)$ \\
\hline Memory & $.45(.54)$ & $.48(.63)$ & $.11(.53)$ & $.40(.49)$ \\
\hline $\begin{array}{l}\text { Executive } \\
\text { Function }\end{array}$ & $.23(.59)$ & $.53(.72)$ & $.12(.62)$ & $.37(.64)$ \\
\hline Attention & $-.10(.46)$ & $.02(.40)$ & $-.13(.49)$ & $-.04(.49)$ \\
\hline
\end{tabular}

Note: unit of change is standard deviations. HCT: Hematopoietic cell transplant, TNP: total neuropsychological performance

Table 3: Changes in Cognitive Domains from Baseline to 6 and 12 Months PostHCT.

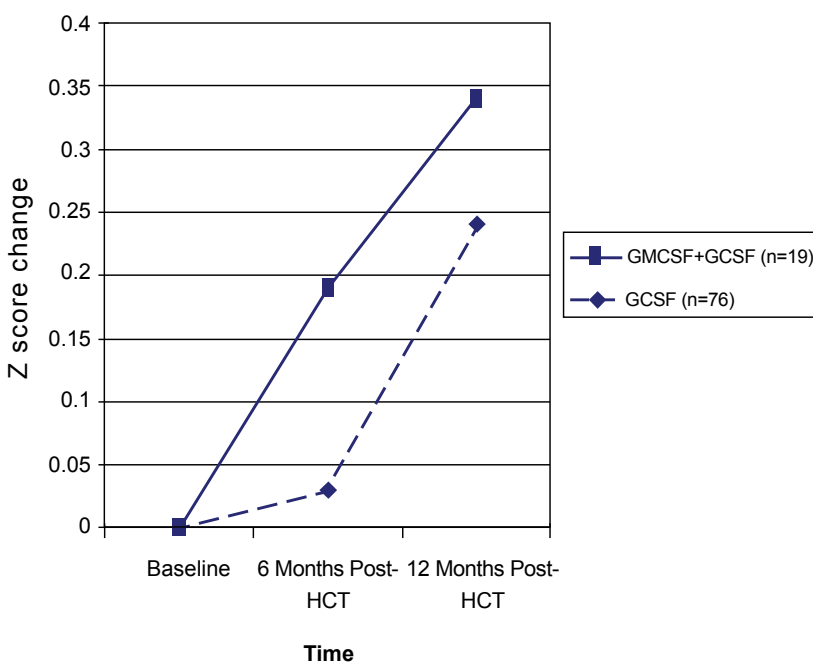

Figure 1: Total Neuropsychological Performance in Hematopoietic Cell Transplant Recipients Receiving GMCSF+GCSF versus GCSF only. The GMCSF+GCSF group performed significantly better at 6 months post-HCT $(p=.04)$, but there were no group differences at 12 months post-HCT $(p=.24)$ The GMCSF+GCSF group improved significantly from baseline to 6 months post-HCT $(p=.01)$ and from baseline to 12 months post-HCT $(p<.01)$. The GCSF group demonstrated no change from baseline to 6 months post-HCT $(p=.33)$ but significant improvement from baseline to 12 months post-HCT $(p<.01)$.

in the GCSF only group $(\mathrm{p}=.33)$. Change in TNP from baseline to 12 months post-HCT was significant in both groups ( $\mathrm{ps}<.01)$. The TNP results were mainly driven by the memory domain; at 6 months, the GMCSF group performed significantly better than the GCSF only group on memory $(\mathrm{p}=.04)$, but there were no group differences in attention and executive function ( $\mathrm{ps}>.48$ ). At 12 months, there were no group differences in any domain (ps>.26). From baseline to 6 months, the GMSCF group improved in memory $(\mathrm{p}<.01)$ while the GCSF group did not improve in any domain (ps $>.07)$. From baseline to 12 months, both groups improved in memory and executive function ( $\mathrm{ps} \leq .01$ ).

\section{Discussion}

The current study examined observational data regarding the relationship between receipt of CSFs and cognition in humans. Findings indicate that receipt of both GMCSF+GCSF was associated with improved cognition in cancer patients receiving HCT, with the inclusion of GMCSF being associated with greater cognitive improvement than GCSF alone. The improvement in cognition was strongest in the memory domain at 6 months and extended to the executive domain by 12 months.
Because study participants were not randomly assigned to receive GMCSF+GCSF versus GCSF alone, and information on cognition of patients with the same diagnosis and who received neither CSF were not available, the results cannot be interpreted as showing a cause-effect relationship between receipt of CSF and cognitive improvement. Nevertheless, because the choice of CSF was based on considerations independent of the disease status of the patient, there is unlikely to be a consistent bias in drug choice that could explain the observed differences in cognitive outcome in patients receiving both GMCSF+GCSF vs GCSF alone. Because the sample size was small, we also cannot rule out the possibility that results are due to sample variability. However, the positive findings in the current study combined with the experimental demonstration that CSFs improve cognition in animals argue for additional research examining CSFs on cognition in humans. This research should consist of well-powered randomized clinical trials to examine the causal effects of GMCSF on cognition in clinical populations. A pilot trial is underway to assess the safety and efficacy of GM-CSF in the treatment of Alzheimer's disease.

The mechanism by which GMCSF and GCSF reverse cognitive deficits in mouse models of $\mathrm{AD}$, and possibly protect RA patients from $\mathrm{AD}$, may be due to reducing amyloid deposition or stimulating angiogenesis, neurite outgrowth, and/or neuronal survival $[7,8]$. Amyloid reduction could result from induced phagocytosis by activated microglia/infiltrating macrophages and neutrophils $[7,8,12,13]$, with macrophages having greater phagocytic ability [14], by induction of MMP-9 from infiltrating macrophages/neutrophils [15-17], by reduced deposition, or by a combination of these mechanisms. In as much as the inflammatory proteins $\alpha 1$-antichymotrypsin and/or apolipoprotein $\mathrm{E}$ are essential for efficient amyloid formation in vitro and in vivo $[5,18,19]$, it is interesting that GMCSF reduces macrophages and/or microglia production of apoE by 3.5 fold, and of the ACT and apoEinducing cytokine Il-1 by 2 fold [20,21], and that cancer patients also over-express IL-1 and IL-6 [22,23]. However, because amyloid deposition in normal subjects arises late in life, the effect of CSF treatment in these cancer patients may be more related to other targets of the innate immune system such as cell debris or glial scar or may arise from induced angiogenesis or neurite outgrowth [7]. Because GCSF and GM-CSF are able to cross the blood brain barrier, the mechanism of cognitive improvement could include both peripheral and direct CNS activities 25-26. The finding that GMCSF + GCSF was associated with greater cognitive improvement than was GCSF alone parallels the finding in $\mathrm{AD}$ mice and may reflect the broader cell type recruitment induced by GMCSF, specifically in the phagocytic monocyte microglial lineage $[7,8]$.

In sum, the data presented here, although preliminary and retrospective, indicate that CSFs, particularly GMCSF, should be further tested as cognition enhancers for a number of different indications including cancer and neurodegenerative disease. The current data provided the basis for an FDA and IRB approved randomized clinical trial currently underway in human $\mathrm{AD}$ patients to evaluate the safety and potential effects of GMCSF on cognition. Thus far no serious adverse events have been recorded.

\section{Acknowledgments}

Supported by grants RSG-01-070-01-PBP from the American Cancer Society to MBJ and AG 25711 to HP, and by the people of Florida through the Byrd Alzheimer's Institute. HP is the Eric Pfeiffer Chair for Research on Alzheimer's disease at USF. HJ is supported in part by the National Cancer Institute grant K07CA138499. No authors have potential conflicts of interest, except to note that the 
Citation: Jim HSL, Boyd TD, Booth-Jones M, Pidala J, Potter H (2012) Granulocyte Macrophage Colony Stimulating Factor Treatment is Associated with Improved Cognition in Cancer Patients. Brain Disorders Ther 1:101. doi:10.4172/2168-975X.1000101

University of South Florida has applied for (but not licensed) a patent on using GMCSF to treat cognitive decline, on which HP and TB are two of the four inventors.

\section{Author Contributions}

Dr. Jim had full access to all of the data in the study and takes full responsibility for the integrity of the data and the accuracy of the data analysis.

Original HCT Study concept and design: Booth-Jones.

CSF-specific data analysis concept and design: Jim, Potter.

Acquisition of the data: Booth-Jones.

Analysis and interpretation of data: Jim, Boyd, Pidala, Potter.

Drafting of manuscript: Jim, Potter.

Critical revision of the manuscript for important intellectual content: Jim, Boyd, Booth-Jones, Pidala, Potter.

Statistical analysis: Jim.

Obtained funding: BoothJones. Potter.

Administrative, technical, or material support: Jim, Boyd, Booth-Jones, Pidala,

Study supervision: Booth-Jones.

\section{References}

1. Harder H, Holtel H, Bromberg JE, Poortmans P, Haaxma-Reiche H, et al. (2004) Cognitive status and quality of life after treatment for primary CNS lymphoma. Neurology 62: 544-547.

2. Le Pechoux C, Laplanche A, Faivre-Finn C, et al. (2011) Clinical neurological outcome and quality of life among patients with limited small-cell cancer treated with two different doses of prophylactic cranial irradiation in the intergroup phase III trial (PCI99-01, EORTC 22003-08004, RTOG 0212 and IFCT 99-01). Ann Oncol 22: 1154-1163.

3. Mangialasche F, Solomon A, Winblad B, Mecocci P, Kivipelto M (2010) Alzheimer's disease: clinical trials and drug development. Lancet Neurol 9 : 702-716

4. McGeer PL, Rogers J, McGeer EG (2006) Inflammation, anti-inflammatory agents and Alzheimer disease: the last 12 years. J Alzheimers Dis 9: 271-276.

5. Potter H, Wefes IM, Nilsson LN (2001) The inflammation-induced pathological chaperones ACT and apo-E are necessary catalysts of Alzheimer amyloid formation. Neurobiol Aging 22: 923-930.

6. ADAPT Research Group, Martin BK, Szekely C, Brandt J, Piantadosi S et al. (2008) Cognitive function over time in the Alzheimer's Disease Antiinflammatory Prevention Trial (ADAPT): results of a randomized, controlled trial of naproxen and celecoxib. Arch Neurol 65: 896-905

7. Boyd TD, Bennett SP, Mori T, Governatori N, Runfeldt M, et al. (2010) GMCSF upregulated in rheumatoid arthritis reverses cognitive impairment and amyloidosis in Alzheimer mice. J Alzheimers Dis 21: 507-518.

8. Sanchez-Ramos J, Song S, Sava V, Catlow B, Lin X, et al. (2009) Granulocyte colony stimulating factor decreases brain amyloid burden and reverses cognitive impairment in Alzheimer's mice. Neuroscience 163: 55-72.

9. Sostak P, Padovan CS, Yousry TA, Ledderose G, Kolb HJ, et al. (2003) Prospective evaluation of neurological complications after allogeneic bone marrow transplantation. Neurology 60: 842-848.

10. Beglinger LJ, Duff K, Van Der Heiden S, et al. (2007) Neuropsychological and psychiatric functioning pre- and posthematopoietic stem cell transplantation in adult cancer patients: a preliminary study. J Int Neuropsychol Soc 13: 172-177.

11. Jacobs SR, Small BJ, Booth-Jones M, Jacobsen PB, Fields KK (2007) Changes in cognitive functioning in the year after hematopoietic stem cell transplantation. Cancer 110: 1560-1567.

12. Boissonneault V, Filali M, Lessard M, Relton J, Wong G, et al. (2009) Powerfu beneficial effects of macrophage colony-stimulating factor on beta-amyloid deposition and cognitive impairment in Alzheimer's disease. Brain 132: 10781092.

13. El Khoury J, Toft M, Hickman SE, Means TK, Terada K, et al. (2007) Ccr2 deficiency impairs microglial accumulation and accelerates progression of Alzheimer-like disease. Nat Med 13: 432-438.
14. Bae HB, Zmijewski JW, Deshane JS, Tadie JM, Chaplin DD, et al. (2011) AMPactivated protein kinase enhances the phagocytic ability of macrophages and neutrophils. FASEB J 25: 4358-4368.

15. Zhao L, Lin S, Bales KR, Gelfanova V, Koger D, et al. (2009) Macrophagemediated degradation of beta-amyloid via an apolipoprotein $\mathrm{E}$ isoformdependent mechanism. J Neurosci 29: 3603-3612.

16. Kohno Y, Tanimoto A, Cirathaworn C, Shimajiri S, Tawara A, et al. (2004) GM CSF activates RhoA, integrin and MMP expression in human monocytic cells Pathol Int 54: 693-702.

17. Jalili A, Shirvaikar N, Marquez-Curtis LA, Turner AR, Janowska-Wieczorek A (2010) The HGF/c-Met axis synergizes with G-CSF in the mobilization of hematopoietic stem/progenitor cells. Stem Cells Dev 19: 1143-1151.

18. Ma J, Yee A, Brewer HB Jr, Das S, Potter H (1994) Amyloid-associated proteins alpha 1-antichymotry psin and apolipoprotein E promote assembly of Alzheimer beta-protein into filaments. Nature 372: 92-94.

19. Wisniewski T, Castaño EM, Golabek A, Vogel T, Frangione B (1994) Acceleration of Alzheimer's fibril formation by apolipoprotein $E$ in vitro. Am J Pathol 145: 1030-1035

20. Murphy GM Jr, Yang L, Cordell B (1998) Macrophage colony-stimulating factor augments beta-amyloid-induced interleukin-1, interleukin-6, and nitric oxide production by microglial cells. J Biol Chem 273: 20967-20971

21. Zuckerman SH, Evans GF, O'Neal L (1992) Cytokine regulation of macrophage apo $E$ secretion: opposing effects of GM-CSF and TGF-beta. Atherosclerosis 96: 203-214.

22. Ahles TA, Saykin AJ (2007) Candidate mechanisms for chemotherapy-induced cognitive changes. Nat Rev Cancer 7: 192-201.

23. Meyers CA, Albitar M, Estey E (2005) Cognitive impairment, fatigue, and cytokine levels in patients with acute myelogenous leukemia or myelodysplastic syndrome. Cancer 104: 788-793.

24. McLay RN, Kimura M, Banks WA, Kastin AJ (1997) Granulocyte-macrophage colony-stimulating factor crosses the blood--brain and blood--spinal cord barriers. Brain 120: 2083-2091.

25. Zhao LR, Navalitloha Y, Singhal S, Mehta J, Piao CS, et al. (2007) Hematopoietic growth factors pass through the blood-brain barrier in intact rats. Exp Neuro 204: 569-573.

26. Delis DC, Kramer JH, Kaplan E (1996) California Verbal Learning Test: Adult Version Manual. San Antonio TX: Psychological Corporation.

27. Wechsler D (1997) Wechsler Memory Scale-III Manual. San Antonio, TX Psychological Corporation.

28. Wechsler D (1981) Wechsler Adult Intelligence Scale-Revised Administration and Scoring Manual. San Antonio, TX: Psychological Corporation.

29. Reitan R, Wolfson D (1993) The Halstead-Reitan Neuropsychological Test Battery: Theory and Clinical Interpretation. Tuscan, AZ: Neuropsychology Press.

30. Benton AL, Hamsher (1989) Multilingual Aphasia Examination. Iowa City, IA AJAAssociates.

31. Trenarry MR, Crosson B, DeBoe J (1989) The Stroop Neuropsychological Screening Test. Lutz, FL: Psychological Assessment Resources.

32. Connors CK (2000) Conners' Continuous Performance Test 3.0. Toronto: MHS 